\title{
Outcomes of transaortic edge-to-edge repair of the mitral valve in patients undergoing minimally invasive aortic valve replacement
}

\author{
Christos G. Mihos, DO, ${ }^{\mathrm{a}}$ Orlando Santana, MD, ${ }^{\mathrm{a}}$ Juan C. Brenes, MD, ${ }^{\mathrm{a}}$ and Joseph Lamelas, MD, \\ Miami Beach, Fla
}

Clinically significant mitral regurgitation (MR) is often found in conjunction with severe aortic valve stenosis. Adding mitral valve surgery to aortic valve replacement (AVR) increases the operative risk. This risk may be reduced by performing a transaortic edge-to-edge repair of the mitral valve during the AVR ${ }^{1-5}$ We describe how to perform this procedure and report our results of using this approach during minimally invasive valve surgery.

\section{METHODS}

After obtaining approval from the Mount Sinai Medical Center Institutional Review Board, we retrospectively reviewed all heart operations performed at our institution to identify patients who underwent minimally invasive AVR and transaortic edge-to-edge mitral valve repair. Intraoperative transesophageal echocardiography was performed immediately before and after the operation, and the MR was graded. Follow-up echocardiograms were obtained to evaluate the MR, and transmitral valve gradients were measured to assess for the presence of mitral stenosis.

\section{Surgical Technique}

During intraoperative transesophageal echocardiography, the MR jet is evaluated at different angles $\left(0^{\circ}, 60^{\circ}, 90^{\circ}, 120^{\circ}\right)$, as well as in the transgastric short-axis view, to determine the origin of the jet. If the MR jet originates in the area of the A2-P2 portions of the mitral valve, the patient is considered a candidate for an edge-to-edge repair.

A femoral platform is used to establish cardiopulmonary bypass in all patients. A 5-cm transverse parasternal incision is made over the third intercostal space, and the fourth costochondral cartilage is transected. Transincisional direct aortic crossclamping is performed with a flexible and retractable shaft crossclamp (Novare Surgical Systems, Cupertino, Calif). A transverse aortotomy is then performed for exposure of the aortic valve. The aortic valve is removed under direct vision. After removal of the aortic valve, the A2 and P2 segments of mitral valve are identified, and an edgeto-edge repair is carried out with a 4-0 Prolene polypropylene (Ethicon, Somerville, NJ) mattress suture placed $1 \mathrm{~cm}$ from the free edge of the mitral valve leaflets and reinforced with Teflon (Ethicon, Somerville, NJ) pledgets on the ventricular side of the mitral valve. In circumstances in which it may be difficult to visualize the mitral valve leaflets, a 5- or $10-\mathrm{mm} 0^{\circ}$ endoscope (Karl Storz, Tuttlingen, Germany) is used to aid in the placement of leaflet sutures. Thereafter, the aortic valve prosthesis is implanted via standard

From the Columbia University Division of Cardiology ${ }^{\mathrm{a}}$ and the Division of Cardiac Surgery, ${ }^{\mathrm{b}}$ the Mount Sinai Heart Institute, Miami Beach, Fla.

Disclosures: Authors have nothing to disclose with regard to commercial support.

Received for publication Dec 7, 2011; revisions received Nov 30, 2012; accepted for publication Dec 12, 2012; available ahead of print Jan 14, 2013.

Address for reprints: Orlando Santana, MD, Echocardiography Laboratory, Columbia University Division of Cardiology, Mount Sinai Heart Institute, 4300 Alton Rd, Miami Beach, FL 33140 (E-mail: osantana@msmc.com).

J Thorac Cardiovasc Surg 2013;145:1412-3

$0022-5223 / \$ 36.00$

Copyright (c) 2013 by The American Association for Thoracic Surgery

http://dx.doi.org/10.1016/j.jtcvs.2012.12.061
}

TABLE 1. Patient baseline characteristics

\begin{tabular}{lc}
\hline Gender & \\
Male & $16(67 \%)$ \\
Female & $8(33 \%)$ \\
Age $(y$, mean \pm SD) & $77.8 \pm 9.2$ \\
Aortic valve lesion & \\
Aortic stenosis & $20(83 \%)$ \\
Aortic insufficiency & $2(8.5 \%)$ \\
Prosthetic valve insufficiency & $2(8.5 \%)$ \\
Mitral valve lesion & \\
Functional & $11(46 \%)$ \\
Degenerative calcification & $10(42 \%)$ \\
Rheumatic & $3(12 \%)$ \\
Reoperation & $8(33 \%)$ \\
Prior CABG surgery & $6(25 \%)$ \\
Prior AVR & $1(4 \%)$ \\
Prior CABG surgery and AVR & $1(4 \%)$ \\
Preoperative MR (grade, median, IQR) & $3(3-4)$ \\
\hline
\end{tabular}

$\overline{S D \text {, Standard deviation; } C A B G \text {, coronary artery bypass graft; } A V R \text {, aortic valve re- }}$ placement; $M R$, mitral valve regurgitation; $I Q R$, interquartile range.

techniques. The transected rib is then reattached to the sternum with a metal plate (Synthes, West Chester, $\mathrm{Pa}$ ) and a fiber wire is placed in a figure-of- 8 fashion.

\section{RESULTS}

A total of 24 consecutive patients were identified, with a mean age of $77.8 \pm 9.2$ years. The median EuroSCORE risk calculation was 12.5 (interquartile range [IQR], 6-23). The aortic valve lesion was classified as aortic valve stenosis in 20 patients, aortic valve insufficiency in 2 patients, and prosthetic aortic valve insufficiency in 2 patients. The mitral valve lesion was classified as functional MR in 11 patients, degenerative calcification in 10 , and rheumatic mitral valve in 3. Eight $(33 \%)$ patients had previous heart surgery, of whom 6 had previous coronary artery bypass graft surgery, 1 had coronary artery bypass with AVR, and 1 had AVR alone (Table 1).

\section{TABLE 2. Operative results}

\begin{tabular}{lc}
\hline Aortic crossclamp time (min, median IQR) & $101(86-116)$ \\
CPB time (min, median, IQR) & $127(109-149)$ \\
Postoperative MR (grade, median, IQR) & $0(0-1)$ \\
Mortality at $30 \mathrm{~d}$ & $1(7 \%)$ \\
Time to follow-up echocardiogram (d, median, IQR) & $13(5-93)$ \\
Follow-up MR (grade, median, IQR) & $1(0-2)$ \\
\hline$I Q R$, Interquartile range; $C P B$, cardiopulmonary bypass; $M R$, mitral valve regurgitation.
\end{tabular}




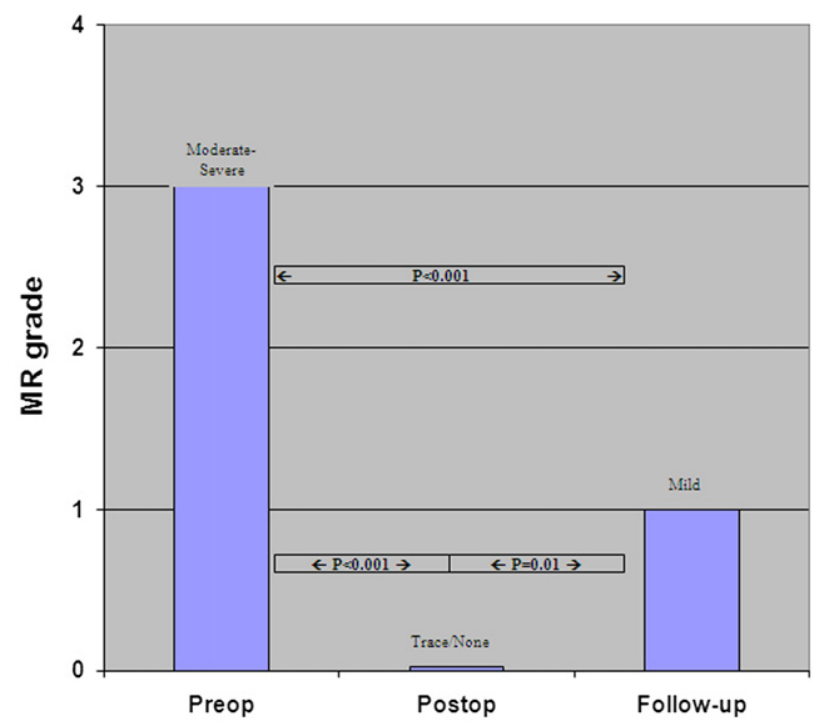

FIGURE 1. Preoperative (Preop), postoperative (Postop), and follow-up mitral valve regurgitation $(M R)$ grade.

There was $1(4 \%)$ operative mortality on postoperative day 23 , resulting from complications from acute renal failure. The median aortic crossclamp time was 101 minutes (IQR, 86-116 minutes) and the median cardiopulmonary bypass time was 127 minutes (IQR, 109-149 minutes). The median preoperative versus postoperative MR grade was 3 (IQR, 3-4) versus 0 (IQR, $0-1$ ), $P<.001$ (Table 2).

The median time to follow-up echocardiogram was 13 days (IQR, 5-93), with 5 patients having no follow-up echocardiography. The mean transmitral gradient was $4.1 \pm 2.7 \mathrm{~mm} \mathrm{Hg}$. Median preoperative versus follow-up MR grade was 3 (IQR, 3-4) versus 1 (IQR, 0-2), $P<.001$. Median postoperative versus follow-up MR grade was 0 (IQR, 0-1) versus 1 (IQR, 0-2) $P=.01$ (Table 2; Figure 1).

\section{DISCUSSION}

Our data demonstrate that in patients undergoing minimally invasive AVR with at least moderate MR originating near the A2-P2 portion of the mitral valve, a transaortic edge-to-edge mitral valve repair is a safe and effective alternative to conventional double valve surgery. The procedure adds approximately 10 minutes to the aortic crossclamp time of an AVR. The patients that did not have this procedure were those with severe mitral annulus and leaflet calcification, which we consider to be contraindications to this procedure.

\section{References}

1. Kavarana MN, Barbone A, Edwards NM, Levinsson MM, Oz MC. Transaortic repair of mitral regurgitation. Heart Surg Forum. 2000;3:24-8.

2. Kim SW, Park PW. Transaortic mitral commissuroplasty with a Bentall procedure or aortic valve replacement. Korean J Thorac Cardiovasc Surg. 2007;40: 727-32.

3. Santana O, Panchamukhi KB, Grana R, Traad EA. Transaortic repair of the mitral valve in patients undergoing aortic valve replacement. Heart Surg Forum. 2009; $12: 1-4$.

4. Santana O, Lamelas J. Minimally invasive transaortic repair of the mitral valve Heart Surg Forum. 2011;14:E232-6.

5. Santana O, Lamelas J. Minimally invasive transaortic mitral valve repair during aortic valve replacement. Texas Heart J. 2011;38:298-300.

\title{
Partial transplant cardiectomy mitral exposure
}

\author{
Scott D. Lick, MD, Daniel L. Beckles, MD, PhD, and Vincent R. Conti, MD, Galveston, Tex
}

\begin{abstract}
Although a traditional groove of Sondergaard left atriotomy incision gives adequate mitral valve exposure in most instances, for difficult cases alternative approaches can be helpful. Radical approaches to the difficult mitral valve through sternotomy have included azygos division with

\footnotetext{
From the Department of Surgery, University of Texas Medical Branch, Galveston, Tex.

Disclosures: Authors have nothing to disclose with regard to commercial support.

Received for publication Nov 9, 2012; revisions received Dec 13, 2012; accepted for publication Jan 14, 2013; available ahead of print Feb 11, 2013.

Address for reprints: Scott D. Lick, MD, Department of Surgery, University of Texas

Medical Branch, 301 University Blvd, Galveston, TX 77555-0528 (E-mail: slick@ utmb.edu).

J Thorac Cardiovasc Surg 2013;145:1413-4

$0022-5223 / \$ 36.00$

Copyright (C) 2013 by The American Association for Thoracic Surgery

http://dx.doi.org/10.1016/j.jtcvs.2013.01.033
}

superior vena cava mobilization, ${ }^{1}$ superior vena cava transection, $^{2}$ and the superior transseptal approach. ${ }^{3,4}$ Drawbacks to these approaches include loss of azygos venous drainage, possible stenosis of the reconstructed superior vena cava, and possible sinoatrial node dysfunction. $^{3,5}$ In a difficult mitral case, however, possible transient sinus node dysfunction is a small trade-off in light of the generally excellent exposure the transseptal exposure provides, and so this approach has become relatively common. Occasionally, though, even the transseptal incision does not provide good mitral exposure through a sternotomy.

The partial cardiectomy approach begins with a standard superior transseptal incision, with bicaval cannulation and caval snares. After aortic crossclamping, the right atrium 